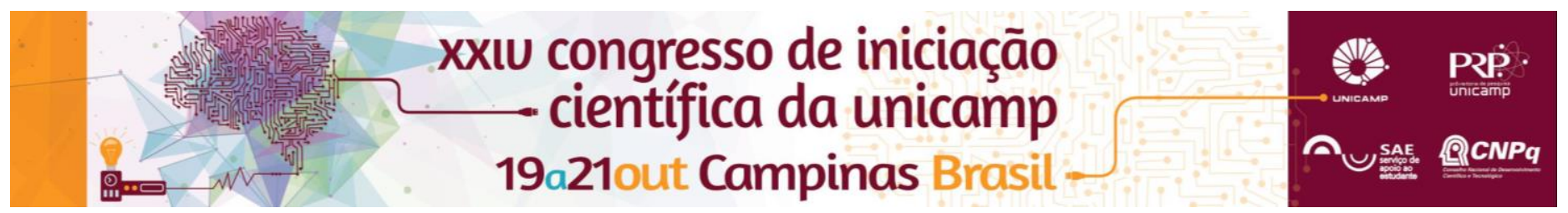

\title{
Produção de nanocompósitos de Mg-LaNi5 por Laminação a Frio
}

\author{
Giovanna M. Erbetta*, Ricardo Floriano.
}

\begin{abstract}
Resumo
Nos últimos anos, nanocompósitos a base de Mg tem sido amplamente estudados para a armazenagem de hidrogênio. Neste trabalho, nanocompósitos de Mg+LaNi5 foram obtidos por laminação a frio seguida de etapa curta de moagem. Duas formas distintas de LaNi5 foram testadas: i) LaNi5 comercial, ii) LaNi5 obtido de bateriais recarregáveis de Ni-HM descartadas em boas e péssimas condições eletroquímicas. A caracterização das amostras de estudo foram realizadas por difração de raios- $X$ e microscopia eletrônica de varredura. Estes resultados revelaram uma estrutura muito refinada com tamanho de cristalito em escala nanométrica, além de uma boa dispersão das parítulas de LaNi5 sobre a matriz de Mg. Curvas cinéticas de ativação, absorção/dessorção de hidrogênio estão sendo obtidas.
\end{abstract}

\section{Palavras-chave:}

Armazenagem de hidrogênio, ligas Mg-LaNi5, laminação a frio.

\section{Introdução}

$\mathrm{O} \mathrm{MgH} 2$ é atrativo para a armazenagem de hidrogênio, visto que possui alta capacidade gravimétrica e o Mg é um metal que possui custo relativamente baixo. Entretanto, sua alta estabilidade e cinética lenta de absorção/dessorção de hidrogênio dificultam suas aplicações práticas. Para superar esses obstáculos, estudos mostraram que a redução do tamanho da partícula, a preparação de nanocompósitos e a introdução seletiva de aditivos, são formas eficientes de se aprimorar as propriedades dos hidretos metálicos $[1,2]$. Neste trabalho, amostras de Mg+LaNi5 foram preparadas por laminação a frio seguida de etapa curta de moagem. Os efeitos de diferentes proporções (\% em massa) de $\mathrm{LaNi}_{5}$ e formas deste material (comercial e extraído de baterias novas e usadas) foram avaliados em consonância com as propriedades de armazenagem de hidrogênio das amostras.

\section{Resultados e Discussão}

As amostras processadas por laminação seguida de moagem são descritas a seguir: $\mathrm{Mg} ; \mathrm{Mg}+20 \% \mathrm{LaNi}_{5}$ Comercial adicionado na moagem; $\mathrm{Mg}+20 \% \mathrm{LaNi}_{5}$ Comercial; $\mathrm{Mg}+35 \% \mathrm{LaNi}_{5}$ Comercial; $\mathrm{Mg}+20 \% \mathrm{LaNi}_{5}$ retirado de bateria nova; $\mathrm{Mg}+35 \% \mathrm{LaNi}_{5}$ retirado de bateria nova; $\mathrm{Mg}+20 \% \mathrm{LaNi}_{5}$ retirado de bateria usada; $\mathrm{Mg}+35 \% \mathrm{LaNi}_{5}$ retirado de bateria usada. $\mathrm{MgH}_{2}$ em excesso foi adicionado em todas amostras durante a etapa de moagem para fins de ativação do $\mathrm{Mg}$. Os difratogramas de raios- $\mathrm{X}$ revelaram a presença das fases $\mathrm{Mg}, \mathrm{LaNi}_{5}$, e $\mathrm{MgH}_{2}$. Uma orientação preferencial na direção dos planos (002) para fase $\mathrm{Mg}$ em decorrência da laminação foi observada em todas as amostras de estudo. O tamanho médio de cristalito das amostras processadas atingiu a ordem nanométrica $(\sim 42,36 \mathrm{~nm})$. As amostras contendo $\mathrm{LaNi}_{5}$ comercial apresentaram também a presença da fase $\mathrm{MgO}$, o que pode ser explicado por uma contaminação que pode ter ocorrido no processo de moagem realizado sob o ar, assim como já foi verificado na literatura [3].

As análises de MEV mostraram, principalmente, a presença de duas fases: uma mais escura e em maior quantidade, que foi identificada pelo EDS como $\mathrm{Mg}$, e outra fase mais clara, finamente distribuída de forma relativamente uniforme, identificada como $\mathrm{LaNi}_{5}$ Observou-se também que a amostra contendo $20 \%$ de $\mathrm{LaNi}_{5}$ comercial adicionado na moagem apresentou uma distribuição muito mais uniforme e íntima do $\mathrm{LaNi}_{5} \mathrm{com}$ a matriz Mg em relação as outras amostras.

Os resultados apresentados aqui ainda são preliminares. As análises das curvas de ativação, absorção/dessorção de hidrogênio estão sendo preparadas.

\section{Conclusões}

Neste trabalho, observou-se que a laminação a frio é bastante efetiva na obtenção de nanocompósitos $(\sim 42,36 \mathrm{~nm})$. Os resultados preliminares das análises de difração de raios-X e microscopia eletrônica de varredura revelaram características positivas para a armazenagem de hidrogênio nas amostras processadas, tais como: intenso refino microestrutural, orientação preferencial, introdução significativa de defeitos e uma dispersão uniforme de partículas de LaNi5 sobre a matriz de Mg.

\section{Agradecimentos}

Ao meu orientador Prof. Dr. Ricardo Floriano, por todo o auxílio e apoio durante o desenvolvimento do projeto.

À Faculdade de Ciências Aplicadas (FCA) da UNICAMP e ao Departamento de Engenharia de Materiais (DEMA) da UFSCar, pelo suporte com os equipamentos utilizados. científica.

Ao $\mathrm{PIBIC} / \mathrm{CNPQ}$, pela bolsa de iniciação

[1] ASSEli, A. A. C.; LEIVA, D.R.; COZENTINO, G.H.; FLORIANO, R.; HUOT, J.; ISHIKAWA, T.T.; BOTTA, W.J. Hydrogen storage properties of $\mathrm{MgH} 2$ processed by cold forging, Journal of Alloys and Compounds, v. 615, p 19-24, 2014

[2] LIU, T.; CHEN, C.; QIN, C.; LI, X. Improved hydrogen storage properties of $\mathrm{Mg}$-based nanocomposite by addition of LaNi5 nanoparticles, International Journal of Hydrogen Energy, v. 39, p. 18273-18279, 2014.

[3] FLORIANO, R.; LEIVA, D.R.; DELEDDA, S.; HAUBACK, B.C.; BOTTA, W.J. MgH2-based nanocomposites prepared by short-time high energy ball milling followed by cold rolling: A new processing route, International Journal of Hydrogen Energy, v. 39, p. 4404-4413, 2014. 